\title{
A Cognitive Approach to L2 Reading Comprehension and the Limits of Description
}

\section{Un enfoque cognitivo a la comprensión de lectura en segunda lengua y los límites de descripción}

Juan David Gómez ${ }^{1}$

Citation/ Para citar este artículo: Gómez J. (2016 A Cognitive Approach to L2 Reading Comprehension and the Limits of Description. Colomb. Appl. Linguist. J., 18(2), pp. 119-130.

Received: 27-Aug-2015 / Accepted: 27-Apr-2016

DOI: http://dx.doi.org/10.14483/calj.v18n2.9080

\begin{abstract}
This article sets out to assess the impact of the descriptive trend in the field of cognitive and metacognitive strategies and $L 2$ reading comprehension. It does so with the intention of determining what the descriptive trend has contributed and what aspects of the field remain underserved. This assessment is carried out by tracing the roots of cognitive approaches in this field, identifying the components of descriptive research, and looking at representative samples and their contributions. The results of this analysis show that the kind of descriptive research that is most prevalent in the field has perhaps reached a saturation point, that it now offers only limited utility to teachers of reading comprehension, and that some excesses in the field may in fact be detrimental to the population that it looks to serve. The possible impact of these findings and suggestions for alternative avenues of future research that can complement the advances that have been made are discussed.
\end{abstract}

Keywords: descriptive research, ESL, metacognitive strategies, reading comprehension

\section{Resumen}

Este artículo busca evaluar el impacto de la tendencia descriptiva en el campo de las estrategias cognitivas y metacognitivas y la comprensión lectora L2. Esto se hace con la intención de identificar los aportes de la tendencia descriptiva y aquellos aspectos del campo que han sido desatendidos. Para este fin, se realiza un rastreo de las raíces de los enfoques cognitivos en este campo, se identifican los componentes de la investigación descriptiva, y se consideran algunos ejemplos representativos y sus aportes. Los resultados de este análisis muestran que el tipo de investigación descriptiva que es más común en el campo tal vez haya alcanzado su punto de saturación, que ahora ofrece sólo una utilidad limitada para los profesores de comprensión lectora, y que algunos excesos en el campo pueden ser de hecho perjudiciales para la población que desea servir. Se discute el posible impacto de estas conclusiones y se proponen algunas sugerencias de caminos alternativos de investigación que puedan complementar los logros ya realizados.

Palabras clave: investigación descriptiva, ESL, estrategias metacognitivas, comprensión lectora

$\overline{1}$ Universidad de Antioquia, Antioquia, Colombia. jdgomez7@gmail.com 


\section{Introduction}

Cognitive approaches to learning, language learning, and reading have a long and fruitful history. Throughout the past thirty years, researchers in a variety of disciplines have been attracted by the possibilities of making learning more effective and efficient through a better understanding of the cognitive components and processes that are involved. By learning more about how we learn, we expect to be able to have a positive impact on the speed and effectiveness of learning, either through knowledge of these processes or through metacognitive strategies that look to optimize these processes for faster more comprehensive learning.

Findings brought about through years of extensive research have shown us that metacognitive strategies improve, to a lesser or greater extent and through mindful instruction and consistent practice, the ability of L2 students to acquire skills and knowledge (Ikeda $\varepsilon$ Takeuchi, 2003; Kazemi, Hosseini, E Kohandani, 2013; Wilson E Bai 2010; Zhou, \& Zhao, 2014). Having reached the initial goal of determining whether or not this area of research is worthwhile, we should now turn our attention to exploring its range and the best methods to help teachers to use these tools. Thus far this focus has received insufficient attention, in part because research continues to be heavily invested in descriptive endeavors.

The ends of a cognitive approach in the field of reading comprehension have always seemed to me to be closely related with providing knowledge and methods that are useful to students and teachers of reading so that they can, more efficiently and effectively, use nonfiction texts in their area of study $^{2}$. The means toward achieving this include a comprehensive understanding of the parts and

\footnotetext{
2 I abstain here from describing this as English for Special Purposes (ESP) because the abundance of literature in the field leads one to conclude that the large and growing number of non-English speaking students who need to read in English as an academic or professional necessity make this field a generic rather than a special purpose. I do not use English for Academic Purposes (EAP) because once these students have left the university their ability to access nonfiction texts in English will remain a powerful determinant in their ability to have access to the means for their personal and professional growth.
}

mechanisms that would appear to be involved in the interaction between student and text. And the primary purpose of achieving this greater understanding is to transform the raw data that is a product of this research into a refined product; into the kind of information that can be beneficial to teachers and students.

This essay intends to show that the pursuit of this understanding, as it has been carried out, has perhaps reached a point where it now undermines the ends that begot it. To accomplish this, I will review representative samples from the literature in the field of metacognitive reading strategies (MCRS), synthesize their findings, and elaborate on the compound effect of their focus and methods ${ }^{3}$. I would like to present here that this effect is too often one of excess; of a surfeit of often redundant and unclear information that in isolation may not serve the needs of teachers and students.

There is substantial overlap between those who apply these strategies to learning, language learning (foreign, second, academic, or special), and reading. I will limit myself to speaking about reading comprehension research with the understanding that other ends may also be intended by the researchers cited and that a strategy, or set of strategies, may effectively serve more than one purpose. Explicit reading strategy implementation begins with training that is centered on those practices that make learners aware of covert processes, understanding, knowledge, and skills over which they need to get control if they are to become effective readers (Cambourne, 1999, p. 126).

\section{A Brief History of the Descriptive Trend}

Toward the end of the 1970s, researchers began to identify the possible benefits of teaching metacognitive strategies to improve, among other things, the levels of reading proficiency of students (Flavell, 1978; Forrest \& Barron, 1977; Markman,

\footnotetext{
3 Although my focus is on the fields of EFL-ESL, I do not distinguish between them because those distinctions are not applicable to the argument behind this paper (Carell, 1998). Similarly, my experience with reading strategies has proven that a high degree of transference between L1 and L2 occurs, hence I will refrain from highlight their differences from here on in (Talebi, 2013).
} 
1978). By the mid and late 1980s, strategy research showed that less competent readers were "able to improve [their level of proficiency] through training in strategies evidenced by more successful readers" (Carell, Pharis, \& Liberto, 1989, p. 648), and researchers corroborated what Flavell and others supposed, that strategy use improved reading comprehension proficiency (Barnett, 1988; Waxman E Padron, 1987).

Early interest by psychologists into the cognitive mechanisms involved in reading quickly flourished into a thriving field of cognitive and metacognitive studies in learning and reading comprehension so that in the last thirty years the field of reading comprehension studies in L1 and L2 has hosted researchers from psychology, sociology, and linguistics. Some of the first signs that point toward descriptive and explanatory research can be found in Flavell's (1979) "Metacognition and Cognitive Monitoring: A New Area of CognitiveDevelopmental Inquiry," in which he writes that "it will... be very important to try to discover the early competencies that serve as building blocks... rather than merely cataloguing... metacognitive lacks and inadequacies" and that "we also need to try to explain development in this area as well as describe it" (p. 909).

In the thirty five years since this article was published, the terms and definitions that he provided, terms and definitions that were robust enough to be of use today, have been atomized, with the intention of achieving greater clarity but, in many cases, the unfortunate result of internal inconsistencies and redundancy. I include Flavell's (1979) definitions of strategies and monitoring here so that they can serve as a point of reference. Cognitive monitoring he defines as: "occurring through the actions and interactions among four classes of phenomena: (a) metacognitive knowledge, (b) metacognitive experiences, (c) goals (or tasks), and (d) actions (or strategies)"(p.906). Cognitive strategies "are invoked to make cognitive progress and metacognitive strategies to monitor it" (p. 909). He also tells us that our "store of metacognitive knowledge is apt to contain knowledge of metacognitive strategies as well as cognitive ones" (p. 909).
Researchers have eagerly followed his suggestion to explain and describe and in doing so have sometimes lost sight of the purpose behind acquiring a more comprehensive understanding of strategies and students. The purpose being that the latter can make use of the former to become more proficient in accessing content (declarative knowledge) or mastering a skill (procedural and conditional knowledge) $)^{4}$. It follows then that one of the primary reasons why reading strategies should be of interest to researchers should be the correlation that exists between the use of strategies and more effective reading comprehension (Carrell, 1998, p. 2).

\section{The Primary Elements Behind Descriptive Research}

By following some of the original designs behind the descriptive approach to reading strategies, we can track how the uncoupling of the means from the ends may have occurred. The means to which I allude are the acquisition and synthesis of information undertaken by researchers and the ends are those goals toward which we all strive: providing tools that will be useful to reading instructors and their students. We can assume that the terminology and classification systems that the descriptive trend has produced were directed at making sense of at least the following three areas: (1) The different kinds of MCRSs and their components; (2) Who is most likely to employ MCRSs and how much do they know about them beforehand; (3) Where they work ${ }^{5}$.

To this end, researchers have come up with expanded definitions for strategies and monitoring. These have come about through observation and measurement of behavior then coinage of a new term or category that serves to describe what the student is doing, thinking, or aiming at as she reads. Some of these terms are very broad, others very

\footnotetext{
4 Metacognition requires learners to use declarative, procedural, and conditional knowledge. Although the unreliable separation by researchers of the declarative and procedural components of strategy instruction is a matter of equal importance, this topic lies just beyond the scope of this essay and must be left for a later time.

5 That they work is generally agreed upon. See Wilson and Bai
} (2010). 
specific, but what cannot be disputed is that there is an overabundance of them (Schellings, 2011). Case in point, Block (1986) touts the success rate of "integrators" versus "non-integrators," Oxford (1990) presents us with a kaleidoscope of learning strategies that she organizes into six different groups: cognitive, metacognitive, memory-related, compensatory, affective, and social. Kern (1997) concludes that the strategies themselves have no intrinsic value and that what matters is how they are contextualized and operationalized, and HampLyons (1985) advises that we distinguish between two different kinds of approaches, a traditional and a text-strategic approach, each of these having no less than eighteen defining features; features such as emphasis on content lexis and glosses.

This is a small but representative sample of the plethora of descriptive information about metacognitive strategies that has been gathered over the past three decades. Despite the evidence however, some researchers remain convinced that although the existent models of classification "can facilitate our current research, a more detailed... taxonomy is still needed" (Zhou \& Zhao, 2014, p. 14). Very quickly one begins to see how the variety and quantity of terms and structures can fail to provide teaching instructors with a north to follow, or lean towards at least. The present volume of taxonomy can be overwhelming and steps should be taken to make it more useful.

\section{The Strategies and the Reading Teacher}

For illustrative purposes, let's suppose that Jane Doe, a graduate student, is assigned to teach a remedial reading course for ESL students at her college. Jane does what we would all want her to do: She decides to learn about new developments in this field so that she can provide her students with the best possible learning experience. From her research, she comes away with the knowledge that procedural knowledge is as important as declarative knowledge, and that a top-down, rather than bottom-up approach has proven to be useful when teaching ESL students but she is unsure about which of the eighteen characteristics of the text strategic approach she should place emphasis on, or whether she should emphasize any of them at all seeing that it is not the strategies themselves but making them operational that matters.

When considering the bottom-up and topdown alternatives, she must be sure to distinguish between those authors who use these terms to refer to the decisions made by readers to focus on micro elements such as lexis and syntax (bottom up) or macro elements such as matters of purpose and structure (Ikeda \& Takeuchi, 2003) and those that use the terms to refer to regulation; authors like Efklides (2011) who does so when discussing the two levels of functioning in Self- Regulated Learning (SRL), namely, person level interactions and task $\mathrm{x}$ person level (p. 7).

In fact, Jane would do well to steer clear of SRL altogether because the strategies of self-regulation; forethought, planning, performance monitoring, and reflection on performance (Pintrich $\mathcal{E}$ Zusho, 2002) are similar enough to cognitive and metacognitive strategies so as to confuse her further and bottom up and top down are similar enough, in fact almost identical, to the lower and higher level processes described by Grabe and Stoller (2002).

Not all of what is available appears this complex. There are some simple strategies that Jane could learn more about and implement in her classroom. Nuttall (1982) advises the use of word-attack skills that include interpreting discourse markers so as to find out the meaning of difficult sentences. We may ask ourselves, though, if this is not a long way to go to describe old fashioned reading. Similarly, Saricoban (2002) echoes others before him when in his three phase approach he advises that "students should be guided to make use of their background knowledge to reach and capture the meaning given in the reading material" (p. 1). It is unlikely, however, that one could read without making use of some background knowledge, and if one reads and does not access the correct background knowledge until prompted by the instructor, that is, until she helps one to "activate it," this may be seen by some as a form of cheating. Cheating precisely because there will be no one to activate the appropriate background knowledge once the semester is through or when the student faces a standardized test. 
One article suggests that "looking for important information" (Khonamri \& Kojidi, 2011) can be useful to students. Like those ideas suggested above, this seemingly logical bit of counsel does not hold up well to scrutiny because it invites us to wonder how the student is to distinguish between that information that is important and that which is not. Being able to tell the two apart is in a sense the definition of a competent reader, which if the student was, she would likely not be in Jane's class. So how large is the pool of information available to Jane? A summary glance over the information that researchers have culled about the students who use strategies can give us an idea.

\section{The Strategies and the Reading Student}

A second area on which descriptive research has focused is the students, and the tool most often used for identifying the use of learning strategies ('determining awareness' as it is referred to within the field) are self-report questionnaires. Schellings writes that as of 2011, there were twenty-one such questionnaires and that the number continues to rise. Among the other tools used are oral interviews, stimulated recall methods, portfolios, the think-aloud method, eye movement measurement, computer log-file method, observation of behavior, trace analysis, and performance assessment (Schellings, 2011). The variety of tools used to assess what is just one component within the descriptive category of MCRS, and the number of types of one of those tools, questionnaires, clearly shows that there exists a great deal of redundancy and/or a lack of focus; we are either using too many of the same kind of tool to measure or, if the tools are all different, then clearly, we are not measuring the same things.

The most egregious cases of ambiguity and of too much raw information can often be found in the questionnaires. In some of these we find the overabundance of terms that Flavell warned could resultin mere cataloguing. Many of the questionnaires in use have organized their strategies into categories that, because of an absence of standardization, can be useful only to those reading reports by authors of said questionnaires or by those who have elected to adopt these categories. One of the more popular questionnaires, Mokhtari and Sheorey's (2002)
Survey of Reading Strategies, has four general categories: global reading strategies, problem solving strategies, support reading strategies, and overall reading strategies. The Metacognitive Awareness of Reading Strategies Inventory (MARSI) designed by Mokhtari and Reichard (2002) shares these four general categories. This would seem like a sign of standardization, regrettably, although these two surveys, SORS and MARSI would appear to have, by virtue of their titles, different objectives in mind. The questions posed in the former are almost identical to the latter, save that they have been repositioned or slightly reworded so that what we have is an example of redundancy and not standardization ${ }^{6}$. This sort of practice is not helpful to Jane Doe, in part because creating distinctions without a difference by giving different names to the same tool generates more material than is warranted by the progress in the field.

An example of a questionnaire that while not affected by redundancy does seem to err by virtue of being overambitious is The State Metacognitive Inventory (SMI) by O'Neil and Abedi (1996) which includes statements for students to agree or disagree with that would challenge the reasoning abilities of many philosophy professors. These include statements like "I was aware of my own thinking" and "I was aware of my trying to understand the test questions before I attempted to solve them" (p. 27).

The Metacognitive Awareness Inventory (MAI) by Schraw and Dennison (1994) divides strategies into two large categories; knowledge of cognition and regulation of cognition. What is not made clear is how one could regulate that which one does not know. What is also unclear is why after having used strategies one would not do so, why one would not regulate, again. Why the researchers elect not to use Flavell's definition of cognitive monitoring which includes metacognitive knowledge as one of the "classes of phenomena" also begs an explanation. Both of the categories in this inventory rely on equally indeterminate subcategories such as "debugging strategies" and "information management strategies." They are indeterminate because they can be used to mean so many things

6 See Appendix A. 
that they run the risk, once one has moved beyond the researchers' paper, of not being of any descriptive use at all.

While some of the taxonomy provided and strategy suggestions come up short because of ambiguity and complexity, the information that researchers provide about who uses these strategies is oftentimes redundant and opaque, thereby providing a murky environment for reading teachers to wade through.

In this sense, the problem that arises for Jane Doe, beyond sifting through complexity, redundancies, and ambiguity, is an absence of useful criteria needed to elect a method or researcher to follow. Without effective integration between specific methods and corresponding goals, with only 'improving reading comprehension' as a target to aim for, it is decidedly difficult for Jane to choose an arrow, or quiver, that will help her and her students achieve their goals. This concern would not appear to be shared by some researchers, if we are to judge by Schellings (2011). His comment, that "both in educational practice and in research different kinds of measuring methods are used to record learning strategies. Obviously, different instruments may lead to differences in data and conclusions" (p. 91), lays bare a concern of ontological importance.

If the methods and conclusions can vary to the point where they are mutually contradictory or can be applied only by the researcher and his team, then what the research is providing the reading instructor with also remains unclear and we ask ourselves: How can this kind of research, descriptive research, in the field of MCRS be used to benefit to those that need it most? It is clear that redundancy, ambiguity, and complexity are no aid and quantity is not a guarantor of quality so that the situation compels us to wonder: How should we rein in the self-propagation of this kind of research and make use of what we have learned to better serve reading teachers and students? It is clear that a lack of standardization is an important challenge to the field. By standardization I mean having discreet points of confluence upon which researchers agree. What these points may be is an open question but a principal one among them should be a more standard terminology that could serve to limit redundancy and ambiguity for all of the parties involved.

\section{Awareness of Strategies}

One constant that many questionnaires share is what is referred to as awareness. Between those articles that define and dissect strategies and those that define and dissect the individuals who use them-University students in Botswana (Magogwe, 2013), elementary school students in Montana (Nelson \& Manset-Williamson, 2006), and high school teachers in Iran (Khonamri \& Salimi, 2010)measuring awareness is something that every reading teacher/researcher knows to be foundational to working with metacognitive strategies. This topic serves as an important example of how a common theme allows us to move forward by questioning how it can be used to the benefit of our students. Some of the questions that the prevalence of awareness measurements elicits, and that are seldom asked are: What exactly is awareness? And, why is it so important to measure it?

The first question can be answered in part by surmising that by carrying out a needs assessment the instructor can (1) open the door to conversation about personal epistemologies and, thus, provide an introduction to MCRS; (2) empower students by highlighting their effective reading habits; those that employ strategies, and (3) gather information as to what topics would need reinforcement and which would need to be taught outright.

To the second question, awareness is a measure of degree, it attempts to gauge how much students know about metacognitive strategies (declarative knowledge), and how much of this knowledge has become procedural and conditional knowledge. What remains unclear is why, if we are to judge by the number of articles that address it, it has become fundamental to the research and to the teaching or learning of strategies intended to improve reading proficiency. In an interdisciplinary comparison, it is unlikely that math teachers, when teaching problem solving heuristics, need to know which of their students have used tables, charts, or graphs or 
whether their students have tried making a model or restating a word problem before they provide instruction, modeling, and practice in the use of these problem solving strategies. The question that remains then is: Why is it that for many researchers in the field of reading comprehension this measurement appears to be the prerequisite to getting on with the simple, and infinitely difficult, task of equipping students with better tools to achieve their academic goals? Have we spent too much time on this topic? Perhaps we have, and perhaps we can now use the bounty of data that is already in existence to draw some general conclusions, to streamline the process for reading teachers and students so that they can readily make use of how awareness can be used in developing their reading targets and classes.

Whereas the present usefulness of the awareness data available can be questioned, the pursuit of quantitative measures that establish a correlation between awareness of metacognitive strategies and reading proficiency, a correlation that has been well established (Everson $\mathcal{E}$ Tobias, 1998; Nietfeld, Cao, E Osborne, 2005; Schraw, 1994; Wilson E Bai, 2010; Young $\varepsilon$ Fry, 2008), is in some sense an appeal to circular reasoning and should perhaps be replaced with other pursuits. If the student knows that she has used certain strategies in the past and that these have helped her to understand the text, then she is likely to (1) use them again; (2) report having used them, and (3) perform better on reading tasks than students who do not use strategies. Therefore, better readers are aware of strategies because they use strategies to be better readers. Despite the logic of this, we may still find articles which conclude that "metacognitively aware readers performed comprehension monitoring with a higher frequency ... whereas low metacognitively aware readers employed comprehension monitoring less frequently" (Khonamri \& Kojidi, 2011, p. 109).

When it comes to strategies, procedural knowledge is likely to precede declarative knowledge. Making the student aware of the latter, that X activity is called prioritizing information for example, can be useful only insofar as it provides a lexicon with which to expand procedural and conditional knowledge, and as we have seen, a shared lexicon for strategies is every day a more elusive goal. It is likely then that these terms can be taught without the use of questionnaires.

A second effort towards quantitative correlation that has not been as useful as it may have been is that which tries to answer whether or not there is a relationship between the use of metacognitive reading strategies and improved reading proficiency. The question is, on the face of it, a relevant one: we want to determine if these tools can be of use so that we may either incorporate them into our curriculum or discard them and look for others. The matter, however, has been largely agreed upon. In 1979 it was supposed that they were in fact useful tools, and dozens of researchers throughout the last thirty five years have corroborated this supposition. Some articles however continue to pursue the question and inevitably reach this same conclusion (Poole, 2009; Quiroga Carrillo, 2010; Willingham, 2006): that the use of these strategies is beneficial to students in their particular microcosm. Some of these efforts may be justified by citing that the question is not simply if they work, but if they work within a specific geographical, cultural, or academic context. The premise behind this is that MCRS that work for students in Montana may not be of use to the students in Botswana. And if this is the case, then students in Botswana cannot be expected to be successful if they transfer to a school in Montana. One cannot have it both ways. A useful tool, like Pythagoras' theorem or metacognitive strategies, have negligible geographical or cultural limits, by presenting our tools as if they do we are implying, wrongly, that they are limited tools indeed.

\section{Conclusions}

Descriptive research has been the predominant line of investigation in the field of metacognitive reading strategies (Chamot, 2004, p. 15). This line of inquiry borders the limits of utility when it produces competing systems of classification that can lead to a more obscure rather than illuminated field. Additionally, by continuing to amass data in the descriptive vein without the concomitant efforts to standardize and synthesize findings so that they may be more user-friendly and less likely to hold 
contradictory or redundant material, we are not facilitating reading instructors in their search for useful and practical tools for use in their classrooms. The paucity of practical results and hence the urgent need for researchers to provide them through the synthesis and classification of existing descriptive research can be observed in the conclusions of Raftari, Seyyedi, and Ismail's (2012) review of 49 articles, conference reports, and books on the topic. The authors tell us that between 1978 and 2009, researchers have concluded that "successful readers use reading strategies more actively" and that "explicit reading strategy instruction is always useful" (p. 29).

There are likely to be many explanations as to why we have reached this saturation point; this imbalance between the supply of theoretical proposals and the demand for practical approaches. I would venture to guess, however, that many of these explanations are strongly linked to the decades-old theory-praxis divide in education. And because the two are related, it is possible that we may contribute to closing the theory-praxis gap by working toward a more equitable relationship between research findings and their classroom implementation. Promising trends that would benefit both of these can be found in efforts to organize teacher education around a core set of skills and practices (Grossman, Hammerness, \& McDonald, 2009), and encouraging teacher educators to take ownership of their theories by testing them in authentic classroom environments (Hughes, 2006). Alternative avenues for future research include prescriptive methods for teaching both teachers and students how to employ strategies. Interest in this area can be found in Cambourne (1999), Farell (2001), Grabe (2002), and Kazemi, Hosseinin, and Kohandani (2013) to name a few. This kind of research must be predicated on clear and explicit goals to be achieved through the use of said strategies. Terms such as decoding the text, meaning making, and identifying relevant information may be too general to be of use unless they are coupled with precise target goals. Specific strategies need to be paired with explicit goals, and these need to be taught through proven methods of instruction.
What are often missing for the reading teacher who looks to the literature for guidance are the connectors that establish meaning and purpose behind the smaller objectives that move toward a general purpose, ideally comprehension of the text. Developing this would allow us to begin to overcome the most common obstacles that surface when we present our students with strategies. These occur when we tell them to decode the relevant parts of text, to activate background knowledge, and to visualize information but we do not tell them, cannot tell them, what parts of the text they should focus on, which knowledge they should activate, and what information they should visualize, which is to say that we frequently present the tools as an end in themselves, to be used because they are useful.

Herein lie some of the possible in-classroom applications of this brief evaluation of the field. Instructors can begin to empower themselves by taking a more active role in the practice-theory economy. This empowerment begins by making the classroom the proving ground for the theories that have been amassed so that we can ultimately learn the extent of their use and, therefore, their value. Theories should serve classroom needs and not vice versa. Instructors can take solace in the fact that the supply of research results far exceeds the number of prescriptive adaptations of the same; in that they need not stay abreast of every new development but rather should select promising tools from within the literature that will further their students' learning goals.

We have accumulated substantial information concerning the what, where, and who of MCRS, and are now in a position to use these resources to address the how and why about them. This article is an invitation toward a change of tack; that we sift through what thirty-plus years of research has provided us with so that we may focus on categorizing and achieving a more efficient standardization of terms, the testing of strategic prescriptive methods, and the production of material that will have a direct impact on helping reading teachers and students achieve their goals. 


\section{References}

Barnett, M. A. (1988). Reading through context: How real and perceived strategy use affects $\mathrm{L} 2$ comprehension. Modern Language Journal, 72, 150-162.

Block, E. L. (1986). The comprehension strategies of second language readers. TESOL Quarterly, 20, 463-494.

Cambourne, B. (1999). Explicit and systematic teaching of reading: A new slogan? The Reading Teacher, 53, 126-127.

Carell, P. (1998). Can reading strategies be successfully taught? The Language Teacher, 22(3). Retrieved from: http://jalt-publications.org/old_tlt/files/98/mar/ carrell.html

Carell, P. L., Pharis, B., \& Liberto, J. (1989). Metacognitive strategy training for ESL. TESOL Quarterly, 23(4), 647-678.

Chamot, A. U. (2004). Issues in language learning strategy research and teaching. Electronic Journal of Foreign Language Teaching, 1, 14-26.

Efklides, A. (2011). Interactions of metacognition with motivation and affect in self-regulated learning: The MASRL model. Educational Psychologist, 46(1), 6-25.

Everson, H. T., \& Tobias, S. (1998). The ability to estimate knowledge and performance in college: A metacognitive analysis. Instructional Science, 26, 65-79.

Farell, T. S. C. (2001). Teaching reading strategies: 'It takes time'. Reading in a foreign language, 13(2), 631-646.

Flavell, J. H. (1978). Metacognition. In E. Langer (Chair), Current perspectives on awareness and cognitive processes. Symposium presented at the meeting of the American Psychological Association, Toronto.

Flavell, J. H. (1979). Metacognition and cognitive monitoring: A new area of cognitive-developmental inquiry. American Psychologist, 34, 906-911.

Forrest, D. L., \& Barron, R. W. (1977). Metacognitive aspects of the development of reading skills. Paper presented at the meeting of the Society for Research in Child Development, New Orleans, LA.

Grabe, W. (2002). Foundations of L2 reading instruction. The Language Teacher, 26(7), 1-4.

Grabe, W., \& Stoller, F. (2002). Teaching and researching reading. Harlow, Essex: Pearson Education Limited.

Grossman, P., Hammerness, K., \& McDonald, M. (2009). Redefining teaching, re-imagining teacher education.
Teachers and Teaching: Theory and Practice, 15(2), 273-289. DOI: 10.1080/13540600902875340

Hamp-Lyons, L. (1985). Two approaches to teaching reading: A classroom-based study. Reading in a Foreign Language, 3, 363-373.

Hughes, J. (2006). Bridging the theory-practice divide: A creative approach to effective teacher preparation. Journal of Scholarship and Teaching, 6(1), 110-117.

Ikeda, M., \& Takeuchi, O. (2003). Can strategy instruction help EFL learners to improve reading ability? An empirical study. JACET Bulletin, 37, 49-60.

Kern, R. G. (1997). L2 reading strategy training: A critical perspective. The AAAL Conference. Orlando, Florida.

Kazemi, M., Hosseini, M., \& Kohandani, M. (2013). Strategic reading instruction in EFL contexts. Theory and Practice in Language Studies, 3(12), 23332342.

Khonamri, F., \& Salimi, M. (2010). The impact of a teacher development program for strategic reading on EFL teachers' instructional practice. PROFILE: Issues in Teachers' Professional Development, 12(2), 107116.

Khonamri, F., \& Kojidi, E. M. (2011). Metacognitive awareness and comprehension monitoring in reading ability of Iranian EFL learners. PROFILE: Issues in Teachers' Professional Development, 13(2), 99-111.

Magogwe, J. M., (2013). Metacognitive awareness of reading strategies of University of Botswana English as second language students of different academic reading proficiencies. Reading $\mathcal{E}$ Writing, 4(1). http:// dx.doi.org/10.4102/rw.v4i1.29

Markman, E. M. (1978). Comprehension monitoring. Paper presented at the Conference on Children's Oral Communication Skills, University of Wisconsin, Madison.

Mokhtari, K., \& Reichard, C. (2002). Assessing students' metacognitive awareness of reading strategies. Journal of Educational Psychology, 94(2), 249-259.

Mokhtari, K., \& Sheorey, R. (2002). Measuring ESL students' reading strategies. Journal of Developmental Education, 25(3), 2-10.

Nietfeld, J. L., Cao, L., \& Osborne J. W. (2005). Metacognitive monitoring accuracy and student performance in the postsecondary classroom. The Journal of Experimental Education, 74(1), 7-28.

Nelson, J. M., E Manset-Williamson, G. (2006). The impact of explicit, self-regulatory reading comprehension strategy instruction on the reading-specific self- 
efficacy, attributions, and affect of students with reading disabilities. Learning Disability Quarterly, 29(3), 213-230.

Nuttall, C. (1982). Teaching reading skills in a foreign language. London: Heinemann.

O’Neil, H. F., \& Abedi, J. (1996). Reliability and validity of a state metacognitive inventory: Potential for alternative assessment. Journal of Educational Research, 89(4), 234-245.

Oxford, R. L. (1990). Language learning strategies: What every teacher should know. New York: Newbury House.

Pintrich, P. R., \& Zusho, A. (2002). The development of academic self-regulation: The role of cognitive and motivational factors. In A. Wigfield $\&$ J. S. Eccles (Eds.), Development of achievement motivation (pp. 249-284). San Diego, CA: Academic Press.

Poole, A. (2009). The reading strategies used by male and female Colombian university students. PROFILE: Issues in Teachers' Professional Development, 11(1), 29-40.

Quiroga Carrillo, C. (2010). Promoting tenth graders' reading comprehension of academic texts in the English class. PROFILE: Issues in Teachers' Professional Development, 12(2), 11-32.

Raftari, S., Seyyedi, K., E Ismail, S.A. (2012). Reading strategy research around the world. International Journal of Humanities and Social Science Invention, 1(1), 24-30.

Saricoban, A. (2002). Reading strategies of successful readers through the three phase approach. The Reading Matrix, 2(3), 1-16.
Schellings, G. (2011). Applying learning strategy questionnaires: Problems and possibilities. Metacognition Learning, 6, 91-109.

Schraw, G. (1994). The effect of knowledge on local and global monitoring. Contemporary Educational Psychology, 19(2) 143-154.

Schraw, G., \& Dennison, R. S. (1994). Assessing metacognitive awareness. Contemporary Educational Psychology, 19(4), 460-475.

Talebi, S. H. (2013). Cross-linguistic transfer (from L1 to L2, L2 to L1, and L2 to L3) of reading strategies in a multicompetent mind. Journal of Language Teaching and Research, 4(2), 432-436.

Waxman, H. C., E Padron, Y. N. (1987). The effect of students' perceptions of cognitive strategies on reading achievement. Paper presented at the annual meeting of the Southwest Educational Research Association, Dallas, TX.

Willingham, T. D. (2006). The usefulness of brief instruction in reading comprehension. American Educator, 50, 39-45.

Wilson, N. S., \& Bai, H. (2010). The relationships and impact of teachers' metacognitive knowledge and pedagogical understandings of metacognition. Metacognition Learning, 5(3), 269-189.

Young, A., E Fry, J. D. (2008). Metacognitive awareness and academic achievement in college students. Journal of the Scholarship of Teaching and Learning, 8(2), 1-10.

Zhou, X., \& Zhao, Y. (2014). A comparative study of reading strategies used by Chinese English majors. English Language Teaching, 7(3), 13-18. 


\section{Appendix A}

Questionnaire Comparison

\footnotetext{
MARSI

1. I have a purpose in mind when I read.

2. I take notes while reading to help me understand what I read.

3. I think about what I know to help me understand what I read.

4. I preview the text to see what it's about before reading it.

5. When text becomes difficult, I read aloud to help me understand what I read.

6. I summarize what I read to reflect on important information in the text.

7. I think about whether the content of the text fits my reading purpose.

8. I read slowly but carefully to be sure I understand what I'm reading.

9. I discuss what I read with others to check my understanding.

10. I skim the text first by noting characteristics like length and organization.

11. I try to get back on track when I lose concentration.

12. I underline or circle information in the text to help me remember it.

13. I adjust my reading speed according to what I'm reading.
}

14. I decide what to read closely and what to ignore.

15. I use reference materials such as dictionaries to help me understand what I read.

16. When text becomes difficult, I pay closer attention to what I'm reading.

17. I use tables, figures, and pictures in text to increase my understanding.

18. I stop from time to time and think about what I'm reading.

19. I use context clues to help me better understand what I'm reading.

20. I paraphrase (restate ideas in my own words) to better understand what I read.

21. I try to picture or visualize information to help remember what I read.

22. I use typographical aids like bold face and italics to identify key information.

\section{SORS}

1. I have a purpose in mind when I read.

2. I take notes while reading to help me understand what I read.

3. I think about what I know to help me understand what I read.

4. I take an overall view of the text to see what it is about before reading it.

5. When text becomes difficult, I read aloud to help me understand what I read.

No equivalent question in SORS.

6. I think about whether the content of the text fits my reading purpose.

7. I read slowly and carefully to make sure I understand what I am reading.

No equivalent question in SORS.

8. I review the text first by noting its characteristics like length and organization.

9. I try to get back on track when I lose concentration.

10. I underline or circle information in the text to help me remember it.

11. I adjust my reading speed according to what I am reading.

12. When reading, I decide what to read closely and what to ignore.

13. I use reference materials (e.g. a dictionary) to help me understand what I read.

25. When text becomes difficult, I re-read it to increase my understanding.

15. I use tables, figures, and pictures in text to increase my understanding.

16. I stop from time to time and think about what I am reading.

17. I use context clues to help me better understand what I am reading.

18. I paraphrase (restate ideas in my own words) to better understand what I read.

19. I try to picture or visualize information to help remember what I read.

20. I use typographical features like bold face and italics to identify key information. 
23. I critically analyze and evaluate the information 21. I critically analyze and evaluate the information presented presented in the text. in the text.

24. I go back and forth in the text to find relationships 22. I go back and forth in the text to find relationships among among ideas in it. ideas in it.

25. I check my understanding when I come across 23. I check my understanding when I come across new conflicting information.

26. I try to guess what the material is about when I read. information.

27. When text becomes difficult, I re-read to increase my understanding.

24. I try to guess what the content of the text is about when I read.

28. I ask myself questions I like to have answered in the text. 26. I ask myself questions I like to have answered in the text.

29. I check to see if my guesses about the text are right or 27. I check to see if my guesses about the text are right or wrong. wrong.

30. I try to guess the meaning of unknown words or phrases.

28. When I read, I guess the meaning of unknown words or phrases. 